\title{
BMJ Open A longitudinal observational study of back pain incidence, risk factors and occupational physical activity in Swedish marine trainees
}

\author{
Andreas Monnier, ${ }^{1,2,3}$ Helena Larsson, ${ }^{1,4}$ Håkan Nero, ${ }^{\odot 5}$ Mats Djupsjöbacka, ${ }^{6}$ \\ Björn O Äng ${ }^{1,2,7}$
}

To cite: Monnier A, Larsson $\mathrm{H}$, Nero $\mathrm{H}$, et al. A longitudinal observational study of back pain incidence, risk factors and occupational physical activity in Swedish marine trainees. BMJ Open 2019;9:e025150. doi:10.1136/ bmjopen-2018-025150

- Prepublication history and additional material for this paper are available online. To view these files, please visit the journal online (http://dx.doi org/10.1136/bmjopen-2018025150).

Received 9 July 2018 Revised 26 February 2019 Accepted 1 March 2019
Check for updates

(C) Author(s) (or their employer(s)) 2019. Re-use permitted under CC BY-NC. No commercial re-use. See rights and permissions. Published by BMJ.

For numbered affiliations see end of article.

Correspondence to Dr Andreas Monnier; andreas.monnier@ki.se

\section{ABSTRACT}

Objectives To evaluate the occurrence of low back pain (LBP) and LBP that limits work ability, to identify their potential early risks and to quantify occupational physical activity in Swedish Armed Forces (SwAF) marines during their basic 4 month marine training course.

Design Prospective observational cohort study with weekly follow-ups.

Participants Fifty-three SwAF marines entering the training course.

Outcomes Incident of LBP and its related effect on workability and associated early risks. Occupational physical activity, as monitored using accelerometers and selfreports.

Results During the training course, $68 \%$ of the marines experienced at least one episode of LBP. This yielded a LBP and LBP limiting work ability incidence rate of 13.5 (95\% $\mathrm{Cl} 10.4$ to 17.8$)$ and 6.3 (95\% Cl 4.2 to 10.0$)$ episodes per 1000 person-days, respectively. Previous back pain and shorter body height $(\leq 1.80 \mathrm{~m})$ emerged as independent risks for LBP (HR 2.5, 95\% Cl 1.4 to 4.3 ; HR $2.0,95 \% \mathrm{Cl}$ 1.2 to 3.3 , respectively), as well as for LBP that limited work ability (HR 3.6, 95\% Cl 1.4 to 8.9; $\mathrm{HR} 4.5,95 \% \mathrm{Cl} 2.0$ to 10.0 , respectively). Furthermore, managing fewer than four pull-ups emerged as a risk for LBP (HR 1.9, 95\% Cl 1.2 to 3.0), while physical training of fewer than three sessions per week emerged as a risk for LBP that limited work ability (HR $3.0,95 \% \mathrm{Cl} 1.2$ to 7.4 ). More than $80 \%$ of the work time measured was spent performing low levels of ambulation, however, combat equipment $(\geq 17.5 \mathrm{~kg})$ was carried for more than half of the work time.

Conclusions Incidents of LBP are common in SwAF marines' early careers. The link between LBP and previous pain as well as low levels of exercise highlights the need for preventive actions early on in a marine's career. The role of body height on LBP needs further investigation, including its relationship with body-worn equipment, before it can effectively contribute to LBP prevention.

\section{BACKGROUND}

Low back pain (LBP) is an epidemiological and clinical problem; it is the leading cause of disability worldwide. ${ }^{1}$ Its nature is commonly recurrent and causes reduction in physical

\section{Strengths and limitations of this study}

- The present unique prospective study design with weekly follow-ups that is conducted early on in the marines' careers is believed to have a strong potential to fill knowledge gaps in low back pain (LBP) epidemiology in marine regiments and similar military units.

- The use of a repeated time-to-event regression method, with discontinued risk intervals, better reflects the recurrent nature of LBP and makes more use of collected data than methods using single time-to-first events as an outcome.

- The definition of a new episode of LBP used in the present study does not distinguish between a new "uniquely" first event and a "symptom flare up" from a recurrent chain of events, which is a problem seen in most studies on back pain or other musculoskeletal pain problems.

- The results for the two physical "max" tests of pullups and kettle-bell lifts are limited to male marines only, as no female marines performed these tests.

activity $^{2}$ and work ability. ${ }^{3}$ Societal groups associated with high levels of physical activity are indeed not spared musculoskeletal problems, and this includes highly trained military units. In fact, approximately $40 \%$ of Swedish Armed Forces (SwAF) marines on active duty experience LBP within a 6 month period, and about half of these experience related limitations in work ability. ${ }^{4}$ This indicates that LBP could have a severe impact on the SwAF marines' operational readiness, as is seen internationally in marine units, ${ }^{5}$ which warrants preventive actions. Given the recurrent nature of $\mathrm{LBP},{ }^{6}$ preventive measures are a high priority and are believed to be most effective early in a marine's career. While the occurrence of and risk factors for musculoskeletal disorders in initial basic military training have been investigated, ${ }^{78}$ the subsequent early phases of a marine's career have 
received less scientific attention; thus the need exists to address this gap in knowledge regarding risks for LBP in active-duty marines.

A high occurrence of musculoskeletal disorders is considered to be present by the SwAF occupational health personnel even during the 4 month SwAF marine training course, where soldiers that have completed basic training are given their first marine-specific training. This physically demanding course focuses on marine-specific occupational tasks, including long range foot patrols with heavy equipment and assault operations from combat crafts (high-speed boats). Given the nature of this first and mandatory part of a marine's career, preventive measures at this stage could have a significant effect on the occurrence of future LBP in this group, and this has long been named a priority research topic in many military nations. Results gained from prospective studies in such communities, where occupational load and tasks are homogeneous and well known, have - we believe - great potential to fill knowledge gaps for further actions in defined military units.

Notably, medical examinations, health appraisals and the evaluation of physical performance are basic routine procedures at the start of a military training course or before deployments. Information from such early examinations along with known risks from civilian contexts, such as a history of previous pain episodes, ${ }^{9}{ }^{10}$ physiological distress or lifestyle factors, ${ }^{10}{ }^{11}$ has the potential to provide relevant risk information in operating activities. While low physical capacity and low performance on military physical fitness tests have previously been indicated as risks for LBP, ${ }^{12} 13$ the screening of marines or similar elite units before entering the course with valid tests for their occupational exposures is not presently performed. New physical screening protocols have indeed been developed and introduced for other SwAF units, covering areas possibly related to the development of LBP in marines as well, for example lifting- and load-carrying capacities. ${ }^{14}$

While detailed knowledge of LBP occurrence and associated risk factors constitutes the foundation for early prevention of LBP within this occupational group, such information has to be interpreted in relation to the occupational physical demands on marines. Here, objective monitoring of occupational physical activity during the marine training course could aid in the interpretation of identified risks. This study therefore aimed to prospectively evaluate the occurrence of LBP and its effect on work ability, as well as to identify potential early risks for such disorders in soldiers during the marine training course. Further aims were to quantify occupational physical activity and work-related exposure during the course.

\section{METHODS \\ Study design}

This study used a prospective observational design with a cohort of SwAF marines entering the 4 month marine training course. A screening programme consisting of a self-administered questionnaire and a battery of physical tests was conducted at the start of the course, while pain occurrences were then followed up on a weekly basis. Occupational physical activity was continuously monitored with accelerometers worn during working hours for 7 weeks of the course by a sub-cohort of participants; this was supplemented by platoon and individual logs of work tasks and physical training. All data collection was conducted at the 1st Marine Regiment, Stockholm, Sweden, between January and May, 2015. The study was approved in advance by the Regional Medical Research Ethics Committee, Stockholm (2014/1904-31/2). After receiving written and oral information on the study, signed informed consent was obtained from all participants prior to enrolment. Measurement occasions and the focus of the different phases of the course are illustrated in figure 1, along with information on the participants' progression throughout the study.

\section{Patient involvement}

Given the defined target group in the present study, no patients seeking medical care were recruited. The present

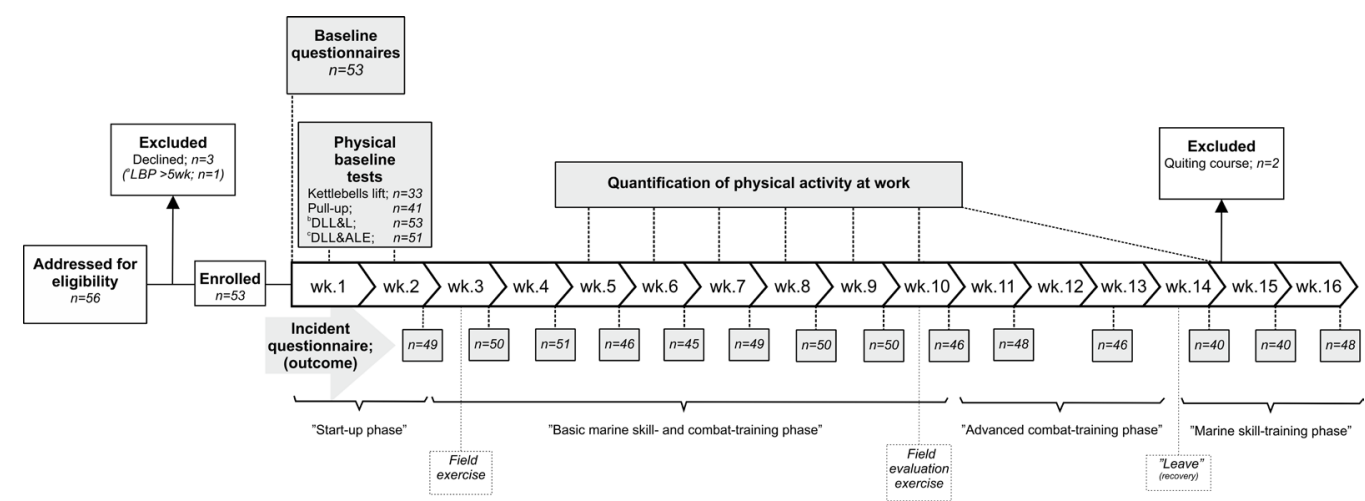

Figure 1 Recruitment and measurement procedure, number of subjects included, excluded and weekly follow-ups during the marine training course. The main focus of the different phases of the course is given together with longer field exercises and leave periods. ${ }^{\mathrm{a}}$ One subject excluded from analysis based on LBP incidence, due to LBP at baseline that lasted for more than additional 5 course weeks. ${ }^{b}$ DLL\&L; Double Leg Lift \& Lower test. 'DLL\&ALE; Double Leg Lift \& Alternate Leg Extension. LBP, low back pain; wk., week. 
research questions and outcomes are based on data/ conclusions from our ongoing translational research on active duty marines ${ }^{415}$; it is also influenced by our empirical knowledge and clinical work in this population. The marines' medical and occupational health services have taken part in planning the data collection, and they constitute the primary way of implementing the results in clinical work for the studied population.

\section{Participants}

To be eligible for inclusion in the present study, marines had to have the intention to complete the entire marine training course. Of 56 eligible marines, 53 met the criterion and were enrolled in the study. The mean (SD) age, body weight, height and body mass index for the enrolled marines were: 21.8 (3.4) years, 80.0 (10.1) kg, $1.82(0.07) \mathrm{m}$ and $24.1(2.5) \mathrm{kg} / \mathrm{m}^{2}$, respectively. The majority of participants $(91 \%, \mathrm{n}=48)$ were men. Ten (19\%) had experienced pain in the lower back within 6 months prior to baseline. Marines with ongoing LBP at baseline lasting for 5 or more consecutive weeks adjacent to the course start $(n=1)$ were excluded from analysis based on incidences.

\section{Measurements and procedure \\ Baseline questionnaires}

Participants initially completed confidential questionnaires to elicit military and demographic background information, ${ }^{4}$ general health ${ }^{16}$ and mental health, ${ }^{17}$ self-assessed work ability ${ }^{16}$ and physical training habits. The questions, which are described in detail in table 1, have previously been used in international and Swedish public health cohorts and studies of active duty SwAF marines. The questionnaires also included detailed information on musculoskeletal pain for nine anatomical areas ${ }^{18}$ within the past week and 6 months, with the following reporting options: For pain within the past week 'No pain' or 'Pain' and for pain within the past 6 months 'No pain', 'Pain a couple of days per month or less' or 'Pain a couple of days per week or more'. Pain limiting work ability was assessed using the options 'Not limited', 'Limited to some extent' or 'Limited to a large extent'.

\section{Physical baseline tests}

Physical tests focusing on muscle strength and movement control were performed during the first 10 days of the course. These tests, described in detail in table 2, were selected on the basis of their use in clinical/preventive work among the studied population or in screening programmes within the SwAF, and have previously been found reliable for use with active duty SwAF marines ${ }^{19}$ or similar SwAF units. ${ }^{14}$ The strength tests, which were conducted following standardised SwAF instructions, ${ }^{14}$ were:

Kettlebell lifts - The number of (correct) lifts of a pair of kettlebells $(2 \times 16,24$ or $32 \mathrm{~kg})$ completed in a $1 \mathrm{~min}$ interval $^{14}$.
Pull-ups - The number of (correct) pull-ups completed, performed hanging from a bar with an overhand (pronated) grip. ${ }^{14}$

These tests were conducted within a series that also including a loaded lower limb functional tes $\mathrm{t}^{20}$ (performed before these tests) and the ranger (loaded) step test ${ }^{21}$ (performed after these tests), which are described in detail elsewhere..$^{20} 21$

The two movement control tests were derived from the descriptions by Comerford and Mottram ${ }^{22}$ and tested for good reliability in SwAF marines. ${ }^{19}$ These tests focus on the ability to actively control or prevent compensatory movement in the lumbar spine, that is, flexion, extension or rotation, while actively moving the lower extremities. The tests, conducted following standardised instructions, ${ }^{19}$ were:

Double Leg Lift $\mathcal{E}$ Lower: The subject, from a supine position, lifts both feet off the bench to a $90^{\circ}$ hip flexion, and then lowers them back to the bench. Any uncontrolled movements in flexion or extension were recorded in the test protocol.

Double Leg Lift $\mathcal{E}$ Alternate Leg Extension (DLLEALE): The subject, from a supine position, lifts both feet off the bench to a $90^{\circ}$ hip flexion, then lowers and straightens one leg to a fully extended position and then back to a $90^{\circ}$ hip flexion. The procedure was then repeated with the other leg, after which both legs were lowered to the starting position. The direction of any uncontrolled movements in extension, flexion or rotation was recorded in the test protocol.

\section{Continuous assessment of work-related physical activity and} occupational tasks

Twenty-seven marines from the inception cohort were randomly assigned by a computer-generated algorithm to wear accelerometers during the course. Six declined, leaving 21 marines in this sub-cohort. They were fitted with tri-axial accelerometers (GT3X+BT, Actigraph, Pensacola, FL) and instructed to wear them on the left hip during all working hours of the course, with the exception of planned prolonged loaded marches (due to the risk of interaction with back pack hip belts resulting in abrasions or compression injuries), aquatic physical training or during training conducted at the marine combat obstacle course (due to water obstacles). They were also instructed to remove them during field exercises conducted at other bases during weeks 11 to 13 of the course due to an inability to collect data at these locations. The accelerometers were initialised using ActiLife software (V.5.5), with data sampling set at a rate of $30 \mathrm{~Hz}$. Information on occupational tasks and equipment worn, and physical training sessions conducted, was recovered from detailed weekly schedules completed by the instructing officers, as well as from the self-reported diaries kept by the marines.

Weekly follow-up

Incidence of musculoskeletal disorders and related effect on work ability were self-reported weekly during the 
Table 1 Self-reported independent variables, the form in which they were included in regression analysis, procedures for retrieving the data and rationale for categorisation

\begin{tabular}{|c|c|c|c|}
\hline Independent variable & Reference & Exposure & Measurement procedure and variable management \\
\hline \multicolumn{4}{|l|}{ Physical characteristics } \\
\hline Body weight & Continuous & & $\begin{array}{l}\text { Body weight (in } \mathrm{kg} \text { ) was self-reported and analysed as a } \\
\text { continuous variable in the models. }\end{array}$ \\
\hline Body height & $>1.80 \mathrm{~m}$ & $\leq 1.80 \mathrm{~m}$ & $\begin{array}{l}\text { Body height was self-reported. Based on the hypothesis } \\
\text { that being either 'too tall or too short' may be negative for } \\
\text { musculoskeletal health in this environment, as previously } \\
\text { identified for this population, }{ }^{4} \text { body height was initially } \\
\text { categorised as } \leq 1.80 \mathrm{~m}, 1.81-1.85 \mathrm{~m} \text { (reference) and } \geq 1.86 \mathrm{~m} \\
\text { (representing body height tertiles of the SwAF marine } \\
\text { population, }{ }^{415} \text { but was reduced to a dichotomised variable due } \\
\text { to no difference between the upper and the reference category } \\
\text { being identified. }\end{array}$ \\
\hline
\end{tabular}

Rated health/health history

Back pain; within 6 months prior to No Yes Self-reported musculoskeletal pain in the lower and/or thoracic course start

back, defined as 'Pain a couple of days per month or less' or 'Pain a couple of days per week or more' within the past 6 months, analysed dichotomised as yes or no as previously for this population. ${ }^{415}$

Hip/knee pain; within 6 months No Yes

Self-reported occurrence of musculoskeletal pain in the hip and/ prior to course start or knee, defined as 'Pain a couple of days per month or less' or 'Pain a couple of days per week or more' within the past 6 months, analysed dichotomised as yes or no, as previously for this population.

Neck/shoulder pain; within No Nes Self-reported musculoskeletal pain in the neck and/or shoulder,

6 months prior to course start defined as 'Pain a couple of days per month or less' or 'Pain a couple of days per week or more' within the past 6 months, analysed dichotomised as yes or no, as previously in this population.

Mental distress (GHQ-12 score) $\quad<4 \quad \geq 4$

The level of mental distress was captured by the GHQ-12, ${ }^{64} \mathrm{a}$ widely used screening instrument developed to detect 'cases' of mental distress. It is a 12-question tool, summed up to give an overall score, ranging from 0 to 12 , and a cut-off of 4 points or more is considered an indication of clinically relevant mental distress. ${ }^{65}$ As such, 'Mental distress' was categorised as $\geq 4$ on the summary GHQ-12 scale.

\section{Work related}

Current work ability with regard to $\geq 9 \quad<9$ best ever

Self-rated work ability captured with the single item question from the work ability index. ${ }^{16}$ Current work ability was rated, with regard to ever best, on a 10-point ordinal scale. Based on the hypothesis that 'less-than-optimal' work ability could constitute a risk in this environment, the responses were dichotomised as high $(\geq 9)$ (reference) and moderate $(<9)$.

Direct from basic military training No Nos
(within 3 months)
(within 3 months)

Physical training habits

Physical training; sessions per week $>2$ sessions/
week

Finishing basic military training within 3 months of the course start was considered a risk, due to the assumption that these soldiers had had less time to adapt to load carriage within the military. Therefore dichotomised as yes or no (reference).

Average number of training sessions per week, exceeding $20 \mathrm{~min}$, were rated on a five point ordinal scale as $\leq 1$ day/ week, 2 days/week, $3-4$ days/week and $\geq 5$ day/week. This item was derived (in addition to an increased number of maximum sessions) from items previously used in several public health cohorts in Sweden. ${ }^{66}{ }^{67} \mathrm{~A}$ U-shaped relationship with LBP was hypothesised for number of physical training sessions per week, i.e. too little and too much training may both be risks for LBP. Consequently, the training sessions per week variable was categorised as $\leq 2$ session/week, 3-4 sessions/week (reference) and $\geq 5$ sessions/week, but reduced to a dichotomised variable for LBP limiting work ability as no significant difference between the upper and reference category was found. 
Table 1 Continued

\begin{tabular}{llll}
\hline Independent variable & Reference & Exposure & Measurement procedure and variable management \\
\hline $\begin{array}{l}\text { Muscular strength training; session } \\
\text { per week }\end{array}$ & $\begin{array}{l}2-4 \text { sessions/ } \\
\text { week }\end{array}$ & $\begin{array}{l}\leq \text { sessions/week } \\
\geq 5 \text { sessions/week }\end{array}$ & $\begin{array}{l}\text { A U-shaped relationship with LBP was hypothesised for number } \\
\text { of strength training sessions per week, that is, too little and too } \\
\text { much training may both be risks for LBP. Consequently Weekly } \\
\text { strength training was categorised as } \leq 1 \text { session/week, 2-4 } \\
\text { sessions/week (reference) and } \geq 5 \text { sessions/week. }\end{array}$ \\
$\begin{array}{lll}\text { Aerobic fitness training; sessions } \\
\text { per week }\end{array}$ & $>1$ session/week $\leq 1$ sessions/week & $\begin{array}{l}\text { Weekly aerobic training was dichotomised as } \leq 1 \text { session/week } \\
\text { or }>1 \text { (reference), given two session per week a priori considered } \\
\text { to be a realistic minimal amount of cardio vascular training } \\
\text { necessary to maintain sufficient aerobic capacity during the } \\
\text { physically demanding basic military training course. }\end{array}$ \\
\hline
\end{tabular}

GHQ, general health questionnaire; LBP, low back pain; SwAF, Swedish Armed Forces.

course, using a short version of the baseline questionnaire. The number of responders for each week is illustrated in figure 1. Weekly follow-ups were not strictly possible due to the geographic location of training during course week 12 , so the follow-up was conducted at the beginning of week 13 and reported as week 12.5 (ie, week 12 and half of week 13).

\section{Outcomes}

LBP was defined as the occurrence of any self-rated pain in the lower back (from the twelfth ribs to the lower gluteal folds ${ }^{23}$ ) within the preceding week, as reported during the weekly follow-up. LBP limiting work ability was defined as the occurrence of any self-rated pain in the lower back within the preceding week that had limited work ability.

For incidence proportions, rates and regression analysis (described in detail below), marines were considered to be at risk for an event as long as they were under observation, and until the occurrence of a LBP event. At the time of pain occurrence, the risk interval was discontinued and marines were not considered to be at risk for a new episode until they were pain-free for the next coming week (if reporting no pain in that week, it was counted; if reporting pain also that week, the week remained censored). Meeting this requirement automatically allowed them to re-enter the analysis (pain observation period). Marines with on-going LBP at baseline were not considered at risk until they were pain-free for at least 1 week, at which point in time they entered the analysis. Late entry was only allowed during the first 4 weeks to accurately reflect the independent variables collected at baseline.

\section{Independent variables}

Independent variables analysed as potential risk factors for LBP and LBP limiting work ability were selected based on existing evidence from active-duty SwAF marines, other military and civilian populations, and empirical knowledge from clinical work with the SwAF marines. These 17 variables, including two physical characteristics, four health-related, two work-related, three on physical training habits and the results of the two strength and the two movement control tests (in flexion and extension), are described in detail in tables 1 and 2.

\section{Confounding variables}

Age, BMI, sex, smoking, non-musculoskeletal co-morbidity and LBP previously during the course were a priori considered possible confounders. A confounder was defined as a variable that, when included during the analytic process, changed the HR of the crude regression model $>20 \%{ }^{24}$

\section{Data management and statistics}

Missing data

The dependent variables, that is, LBP and LBP limiting work ability, were missing for $11 \%$ of the data due to subjects' lost to follow-up during the course. Also, of the independent variables, the kettlebell lift tests were missing for $30 \%$, the pull-ups $23 \%$ and the DLL\&ALE test $4 \%$, due to participants not being able (or allowed) to perform the test at baseline (illness such as having a cold or other infection in $44 \%$ of these and pain or similar co-morbidity in 56\%). All female marines $(n=5)$ missed the kettlebells lift and the pull-ups tests due to illness or on-going pain. Based on the analysis of the missing data mechanism, ${ }^{25}$ however, the data for outcomes and the DLL\&ALE test were considered to be "missing completely at random' (ie, the reason for data to be missing was not dependent of the missing data itself nor predicted by the independent variables included the analysis) and missing data on the kettlebell lift and the pull-ups tests to be 'covariate missing completely at random' (missing data predicted by bodyweight and body height). Multiple imputations by Markov chain Monte Carlo, with random draws based on Jeffreys prior distribution, were used to generate 50 imputed datasets with completed data on all predictor variables, on which the pooled analyses were based. ${ }^{26}$ Given that no female marines performed the two strength tests, imputing values for females based on data from only male marines on these tests might affect the accuracy of the imputation. Therefore, regressions including these two tests were repeated, as part of the sensitivity analysis, on only complete cases, as well as on multiple imputed data with females excluded. 
Table 2 Physical test; independent variables, the form in which they were included in regression analysis, procedures for retrieving the data and rationale for categorisation

\begin{tabular}{|c|c|c|c|}
\hline Independent variable & Reference & Exposure & Measurement procedure and variable management \\
\hline
\end{tabular}

Kettlebells lift; $\mathrm{kg} x \quad>760 \quad \leq 760 \quad$ Pairs of kettlebells weighing 32,24 or $16 \mathrm{~kg}$ each were used. The

repetitions intended test weights were $2 \times 32 \mathrm{~kg}$, but subjects unable to perform

the test safely with these loads could choose the lighter kettlebells.

To make sure that the correct and safe lifting technique was used, all participants performed two test-lifts using a lower weight while being supervised by the test leader. The test measured the number of (correct) lifts of the weights performed in $1 \mathrm{~min}$. Based on the assumption that marines with the lowest lifting capacity are at greater risk of LBP, the lower tertile of the product of 'numbers of lifts $x$ weight lifted' was compared with the upper two tertiles (reference).

\begin{tabular}{|c|c|c|c|}
\hline $\begin{array}{l}\text { Pull-up; number of } \\
\text { repetitions }\end{array}$ & $\geq 4$ & $\leq 3$ & $\begin{array}{l}\text { Hanging from a pull-up bar, using an overhand grip with hands placed } \\
\text { shoulder-width apart, the participants lifted their body until their } \\
\text { chin was level with the bar. The number of (correct) lifts performed } \\
\text { in } 1 \text { min was recorded in the test protocol. The number of correct } \\
\text { 'chins' is dichotomised as } \leq 3 \text { or } \geq 4 \text { (reference). Internationally, the } \\
\text { cut-off for passing a pull-up test during yearly physical assessments } \\
\text { for marines ranges from } 3 \text { (US marines) to } 5 \text { (Royal Marines) and as } \\
\text { such, assuming that marines with the lowest pull-up capacity are at } \\
\text { greater risk of LBP, the cut-off for the reference category was set at } \\
\text { the median, } \geq 4 \text { pull-ups (reference). }\end{array}$ \\
\hline
\end{tabular}

Movement control tests

To make sure failure of any of the movement control tests was due to a 'real' inability to control direction and not unfamiliarity with the test movement, all participants performed the test three to six times with feedback from the tester to ensure familiarisation. To monitor the movement of the lumbar spine, an air-filled pressure sensor (Pressure Biofeedback Unit, Chattanooga Group, Hixson, TN) was placed under the lower back.

\begin{tabular}{|c|c|c|}
\hline Double Leg Lift \& Lower & pass & $\begin{array}{l}\text { The test assesses the ability to prevent extension and flexion of the } \\
\text { lumbar spine. }{ }^{22} \text { The subject, from a supine position, lifts both feet } \\
\text { off the bench to a } 90^{\circ} \text { hip flexion, and then lowers them back to the } \\
\text { bench. Any uncontrolled movements in flexion or extension, defined } \\
\text { as an } \geq 5 \mathrm{~mm} \mathrm{Hg} \text { change (from the starting pressure of } 40 \mathrm{~mm} \mathrm{Hg} \text { ), } \\
\text { were recorded on the test protocol. Test performance on flexion and } \\
\text { extension assessed in the tests was analysed as pass or fail. }\end{array}$ \\
\hline $\begin{array}{l}\text { Double Leg Lift \& } \\
\text { Alternate Leg Extension: }\end{array}$ & pass & $\begin{array}{l}\text { The test assesses the ability to prevent extension, flexion and rotation } \\
\text { of the lumbar spine, and leg abduction, lateral rotation and hip } \\
\text { forward glide. }{ }^{22} \text { The subject, from a supine position lifts both feet off } \\
\text { the bench to a } 90^{\circ} \text { hip flexion, then lowers and straightens one leg to } \\
\text { a fully extended position and then back to a } 90^{\circ} \text { hip flexion, before } \\
\text { repeating the test on the other side. The direction of any uncontrolled } \\
\text { movements, defined as } \geq 5 \mathrm{~mm} \mathrm{Hg} \text { change (from the starting pressure } \\
\text { of } 40 \mathrm{~mm} \mathrm{Hg} \text { ), was recorded on the test protocol. Test performance for } \\
\text { flexion and extension assessed in the tests was analysed as pass or } \\
\text { fail. }\end{array}$ \\
\hline
\end{tabular}

LBP, low back pain.

Descriptive statistics

$\angle B P$ and LBP limiting work ability

Weekly prevalence was analysed as a percentage of those under observation, with $95 \%$ CI. ${ }^{27}$ Weekly incidence of LBP and LBP limiting work ability was analysed as a percentage of those at risk, with a $95 \%$ CI. ${ }^{27}$ The incidence rate of LBP and LBP limiting work ability during the course was calculated based on the number of episodes and the time at risk, presented as episodes per 1000 person-days, with a corresponding $95 \% \mathrm{CI}^{28}$

\section{Work-related physical activity and occupational tasks}

Accelerometer data were analysed only if sufficient wear time could be established, which was defined as at least $180 \mathrm{~min}$ of wear time per day (for full work days) on at least three workdays (for a 5 day week). Non-wear 
time within days was identified by algorithms suggested by Choi et al. ${ }^{29}$ For valid wear time, vertical counts per minute (cpm) (where the arbitrary unit of counts is the filtered raw acceleration generated by body movements and captured by the accelerometer) - based on $10 \mathrm{~s}$ epochs - were extracted and reported as minutes and percentage of total work time, and work time per week spent in these predefined categories: 0 to 99; 100 to 2019; 2020 to 5998 and $5999 \mathrm{cpm} .{ }^{30}$ Here, the category of 2020 to $5998 \mathrm{cpm}$ was considered to be comparable to slow to brisk walking $(\sim 3.8$ to $7.5 \mathrm{~km} /$ hour). ${ }^{31}{ }^{32}$ In addition, the percentage of the workday spent in these categories was reported for time with and without load carriage (combat equipment, $\geq 17.5 \mathrm{~kg}$ ), as identified from the detailed schedules (verified against activity $\operatorname{logs}$ ). Evaluation and comparison with work schedules were performed visually.

\section{Regression analysis}

We used the Andersen-Gill repeated time-to-event regression method ${ }^{33} 34$ with the robust sandwich variance estimator, ${ }^{35}$ and discontinuous risk intervals, ${ }^{34}$ as defined above, to examine the predictive association between the independent variables and LBP. The results are reported as HR with a corresponding 95\% CI. Second, this method was applied to examine the predictive association between independent variables and LBP limiting work ability.

Independent variables were analysed in two blocks. First, physical characteristics, work- and health-related variables, as identified with univariate time-to-event regressions to be associated with the dependent variable, at the level of $\mathrm{p}<0.20$, were included in a multivariable time-toevent regression model. This was followed by an iterative, purposeful selection process of deleting non-significant variables at $p>0.05$. The model was then refitted and verified until a final model contained only significant $(p<0.05)$ independent variables, identified confounders and significant $(p<0.05)$ interactions (between independent variables in the final model and/or independent variables and confounders) ${ }^{24}$ This process was repeated for the clinical tests, with the addition of the significant physical characteristics, work- and health-related risk factors addressed as additional potential confounders. Due to the relatively small sample size, the CI for borderline significant independent variables was inspected (ie, inspection of the lower limit $\mathrm{CI}$ in relation to the size of effect estimate) for indications of incorrect omission from final models. ${ }^{36}$ All final models were deemed to have sufficient CI coverage, based on the events-per-variable ratio. ${ }^{36}$ Using methods described by Cleves et al, ${ }^{37}$ final models showed no violations of underlying assumptions of proportional hazards (eg, tests based on reestimation, interaction of analysis time with the independent variables and graphically through Schoenfeld residuals) and showed appropriate model fit. Analysis was performed using Stata statistical software (V.13.1).
Table 3 Demographic characteristics, physical characteristics and self-rated health at baseline

\begin{tabular}{lcc}
\hline & Mean & SD \\
\hline Age (years) & 21.8 & 3.4 \\
\hline Body weight $(\mathrm{kg})$ & 80.0 & 10.1 \\
Body height $(\mathrm{m})$ & 1.82 & 0.07 \\
Body mass index $\left(\mathrm{kg} / \mathrm{m}^{2}\right)$ & 24.1 & 2.5 \\
GHQ-12 Score & 1.8 & 1.6 \\
$\begin{array}{lc}\text { Muscular strength training; } \\
\text { hours per week }\end{array}$ & 4.5 & 2.7 \\
$\begin{array}{l}\text { Aerobic fitness training; hours } \\
\text { per week } \dagger\end{array}$ & 3.1 & 1.9 \\
\hline & $\%$ & $\mathbf{9 5 \%} \mathbf{C l}$ \\
\hline
\end{tabular}

\begin{tabular}{lcc}
\hline Smoking & & \\
$\quad$ No & 71.7 & 58.4 to 82.0 \\
\hline Occasionally & 28.3 & 18.0 to 42.6 \\
$\begin{array}{l}\text { Yes } \\
\text { Snus (smokeless tobacco) }\end{array}$ & 0.0 & 0.0 to 6.8 \\
$\quad$ No & 64.2 & 50.7 to 75.7 \\
\hline Occasionally & 11.3 & 5.3 to 22.6 \\
\hline Yes & 24.5 & 14.9 to 37.6 \\
\hline Baseline testing & Mean & SD \\
\hline Pull-ups & 7.8 & 5.2 \\
\hline Kettlebell lifts & 17.6 & 6.4 \\
\hline $\begin{array}{l}\text { Average lifts } \\
\text { Kettlebell, average weight } \\
\text { (x2) }\end{array}$ & 29.8 & 4.1 \\
\hline & $\%$ & $95 \% \mathbf{C l}$ \\
\hline
\end{tabular}

Movement control tests, per

direction;

\begin{tabular}{|lll}
\hline DLL\&L flex; fail & 19.2 & 10.8 to 31.9 \\
\hline DLL\&L ext; fail & 34.6 & 23.2 to 48.2 \\
\hline DLL\&ALE flex; fail & 19.6 & 11.0 to 32.5 \\
\hline DLL\&ALE ext; fail & 43.1 & 30.1 to 56.7
\end{tabular}

${ }^{*}$ Average weekly hours of muscular strength training during previous 6 months (median [IQR] all, 4 [3.5]; males, 4 [3.5]; females, 3 [3]).

†Average weekly hours of aerobic fitness training during previous 6 months (median [IQR] all, 3 [2]; males, 3 [2]; females, 5 [3]).

Reported with mean and SD or percentage and corresponding 95\% Wilson score $\mathrm{Cl}(95 \% \mathrm{Cl})$.

DLL\&L, Double Leg Lift \& Lower; DLL\&ALE, Double Leg Lift \& Alternate Leg Extension; GHQ, general health questionnaire.

\section{RESULTS}

Table 3 presents demographic and background data as well as self-rated general health for the 53 marines who completed the baseline questionnaire $(96 \%$ response rate). Good or excellent current health status was reported by $>95 \%$ of respondents. Of the 53 marines starting the course, $49 \%$ joined directly from basic military training, 


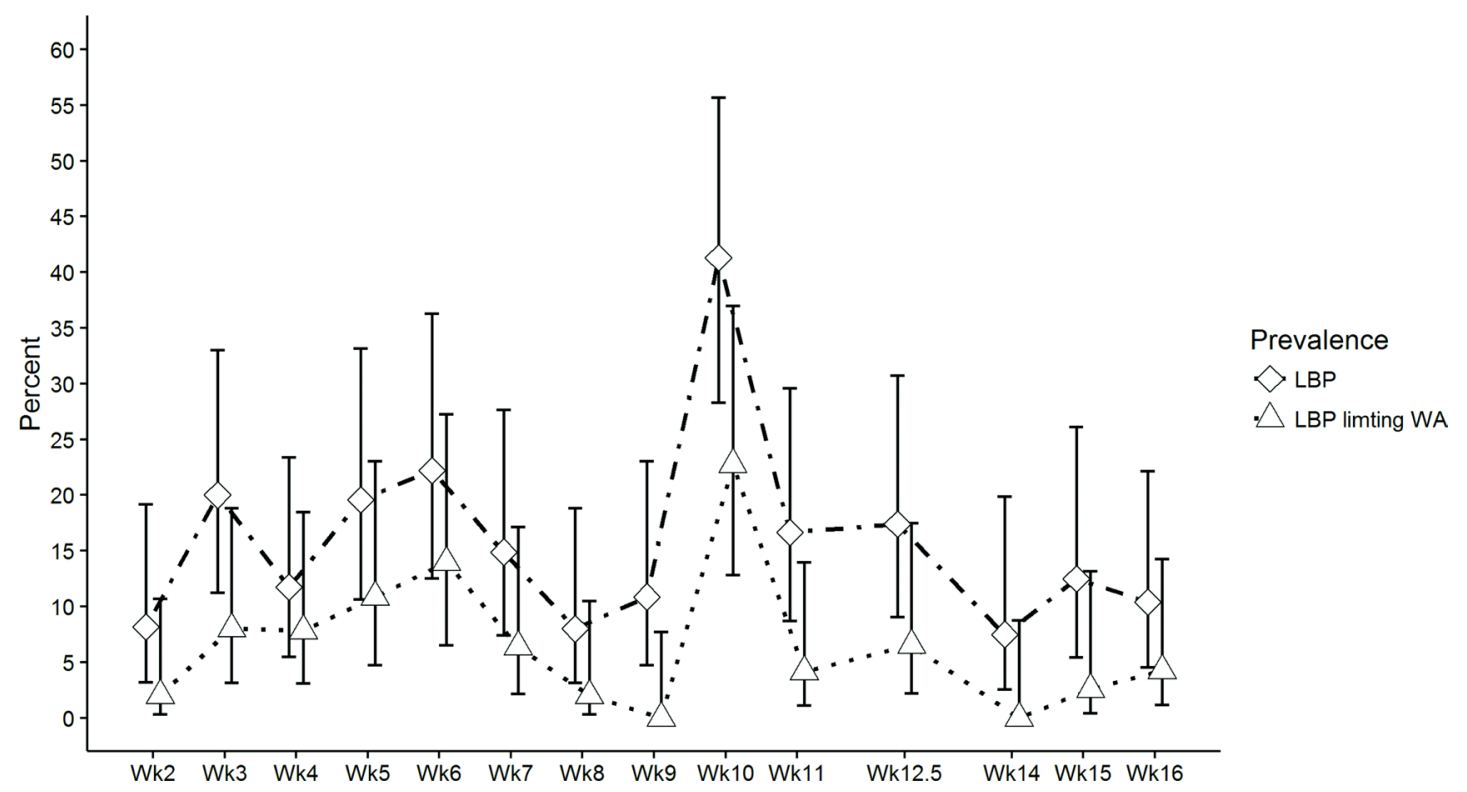

Figure 2 Weekly prevalence of LBP and LBP limiting work ability during the marine training course, reported as weekly proportion (percent) of cohort under study. Error bars indicate 95\% Cl. LBP, low back pain; WA, work ability; Wk, week.

while the other $51 \%$ came from previous service in the SwAF or from a period of civilian occupation/studies.

\section{LBP and LBP limiting work ability}

Figures 2 and 3 present the prevalence and incidence of LBP and LBP limiting work ability, expressed per week during the marine training course. A total of $68 \%$ of the marines experienced at least one episode of LBP during the course, of whom $57 \%$ reported related limitations in their ability to work. The average LBP episode consisted of 1.6 weeks of reported pain, with $42 \%$ of the sufferers experiencing at least one recurrent episode (with an average of 2.8 weeks without reporting pain between episodes). This gave an LBP incidence rate of 13.5 (95\% CI 10.4 to 17.8) episodes per 1000 person-days. For LBP limiting work ability the corresponding incidence rate was 6.3 (95\% CI 4.2 to 10.0). For comparison, incidence rates based on time-to-first event (during the course) are presented in online supplementary data 1 .

\section{Risk factors for LBP and LBP limiting work ability}

Individual physical characteristics, work- and health-related risk factors

Tables 4 and 5 present the results from univariate, final unadjusted and final adjusted multivariable recurrent-event regression models for LBP and LBP limiting

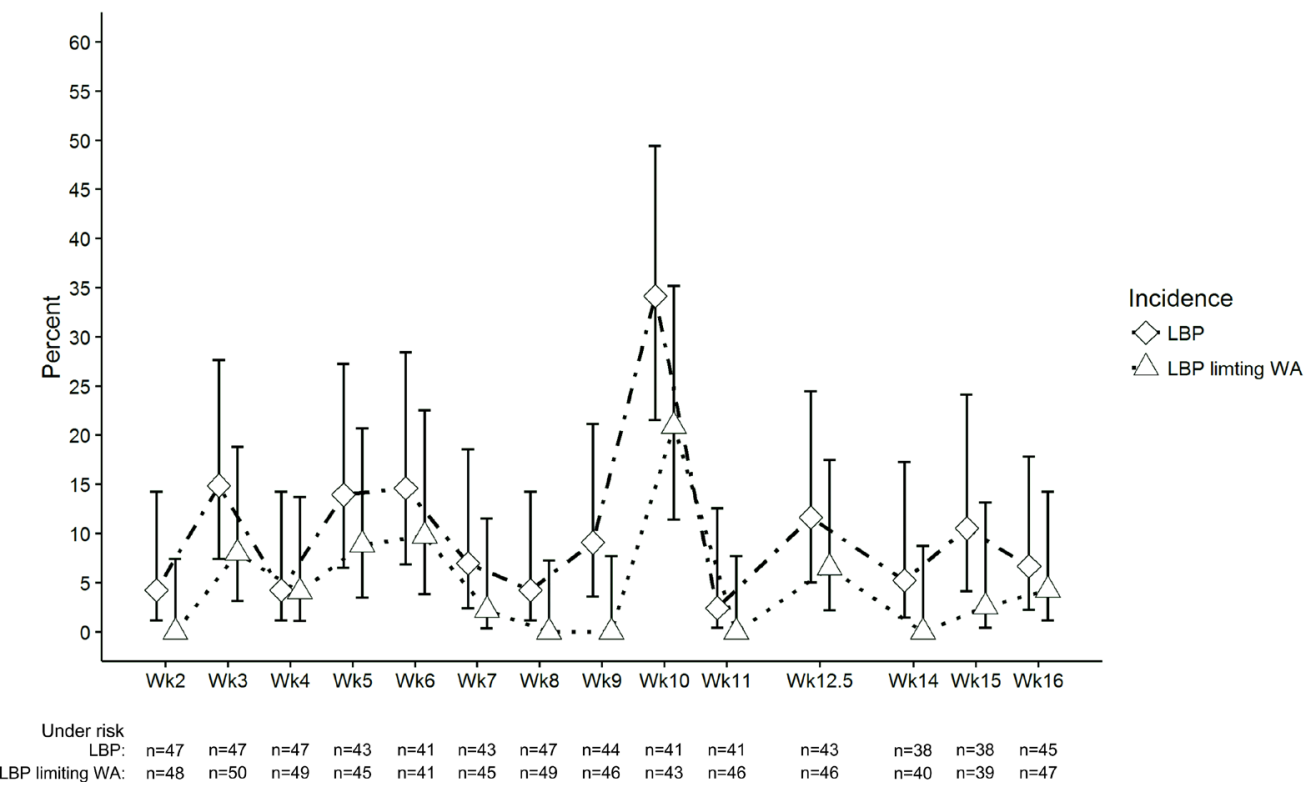

Figure 3 Weekly incidence of LBP and LBP limiting work ability during the marine training course, reported as weekly proportion (percent) of new pain episodes of marines at risk for a new event. Error bars indicate $95 \% \mathrm{Cl}$. LBP, low back pain; WA, work ability; Wk, week. 
Table 4 Regression analyses of individual physical characteristics, work- and health-related risk variables: univariate and multiple final adjusted ${ }^{\dagger} \mathrm{HR}$ for low back pain during the marine training course

\begin{tabular}{|c|c|c|c|c|c|c|c|c|c|}
\hline \multirow[b]{2}{*}{ Variable } & \multicolumn{3}{|c|}{ Univariate } & \multicolumn{3}{|c|}{ Final crude multivariable } & \multicolumn{3}{|c|}{ Final adjusted multivariable* } \\
\hline & HR & $95 \% \mathrm{Cl}$ & $P$ value & HR & $95 \% \mathrm{Cl}$ & $P$ value & HR & $95 \% \mathrm{Cl}$ & $P$ value \\
\hline \multicolumn{10}{|l|}{ Physical characteristics } \\
\hline Body weight (kg) & 1.01 & 0.99 to 1.03 & 0.441 & & & & & & \\
\hline Body height $\leq 1.80(\mathrm{~m})$ & 1.48 & 0.84 to 2.58 & 0.172 & 1.73 & 1.03 to 2.92 & 0.040 & 1.98 & 1.19 to 3.29 & 0.009 \\
\hline \multicolumn{10}{|l|}{ Rated health/health history } \\
\hline $\begin{array}{l}\text { Mental distress } \\
\text { (GHQ-12 Score) }\end{array}$ & 2.08 & 0.65 to 6.70 & 0.219 & & & & & & \\
\hline Back pain; within 6 months prior to course start & 2.00 & 1.09 to 3.64 & 0.025 & 2.26 & 1.27 to 4.03 & 0.006 & 2.47 & 1.41 to 4.31 & $<0.001$ \\
\hline $\begin{array}{l}\text { Hip/knee pain; within } 6 \text { months prior to course } \\
\text { start }\end{array}$ & 1.50 & 0.85 to 2.66 & 0.163 & & & & & & \\
\hline $\begin{array}{l}\text { Neck/shoulder pain; within } 6 \text { months prior to } \\
\text { course start }\end{array}$ & 1.63 & 0.91 to 2.90 & 0.098 & & & & & & \\
\hline \multicolumn{10}{|l|}{ Work-related } \\
\hline Current work ability with regard to best ever & 1.69 & 0.97 to 2.94 & 0.064 & & & & & & \\
\hline $\begin{array}{l}\text { Direct from basic military training (within } \\
3 \text { months) }\end{array}$ & 1.08 & 0.62 to 1.91 & 0.779 & & & & & & \\
\hline \multicolumn{10}{|l|}{ Physical training habits past 6 months } \\
\hline \multicolumn{10}{|l|}{ Physical training; } \\
\hline$\leq 2$ sessions/week & 1.18 & 0.53 to 2.64 & 0.692 & & & & & & \\
\hline 3-4 sessions/week & 1.00 & & & & & & & & \\
\hline$\geq 5$ sessions/week & 1.29 & 0.70 to 2.37 & 0.418 & & & & & & \\
\hline \multicolumn{10}{|l|}{ Muscular strength training; } \\
\hline$\leq 1$ sessions/week & 0.90 & 0.52 to 1.54 & 0.690 & & & & & & \\
\hline 2-4 sessions/week & 1.00 & & & & & & & & \\
\hline$\geq 5$ sessions/week & 1.27 & 0.58 to 2.78 & 0.542 & & & & & & \\
\hline \multicolumn{10}{|l|}{ Aerobic fitness training; } \\
\hline$\leq 1$ session/week & 1.24 & 0.66 to 2.36 & 0.502 & & & & & & \\
\hline
\end{tabular}

${ }^{*}$ Adjusted for confounding effect of sex.

$\mathrm{GHQ}$, general health questionnaire.

work ability during the course. Back pain (lumbar and/ or thoracic back pain) within 6 months prior to the marine training course and shorter body height $(\leq 1.80 \mathrm{~m})$, adjusted for the confounding effect of sex (LBP and LBP limiting work ability) and previous neck shoulder pain (LBP limiting work ability), were identified as independent risks. Additionally, less than three sessions per week of physical training was a significant risk for LBP that limited work ability. No interactions between the independent variables, nor with the confounders, emerged as significant in any of the models. Inspecting the $95 \%$ CI of excluded variables did not indicate any non-correct exclusion of potential risk factors. For comparison, initial multiple models for LBP and LBP limiting work ability are presented with $95 \%$ CI in online supplementary data 2.

\section{Clinical tests}

Performing fewer than four pull-ups (HR 1.9, 95\% CI 1.2 to 3.0), adjusted for confounding effect of previous $B P$ and body height, was identified as a significant risk for LBP. However, no clinical tests were associated with LBP limiting work ability at $\mathrm{p}<0.05$. Final unadjusted and adjusted models for LBP limiting work ability are presented in online supplementary data 3 and 4 . Sensitivity analysis based on complete cases and imputed data, with only males, caused only marginal changes in the results, with no effect on inference.

\section{Work-related physical activity and occupational tasks}

Of the 7 weeks of measurement, five contained sufficient wear time that could be fully used for analyses. During these weeks, an average of $16 \%$ of the working time ( $73 \mathrm{~min}$ per day) (not including long-distance march training, combat obstacle course or aquatic training, with a weekly average of additionally 2 hours), was spent in physical activity of at least moderate intensity, that is 2020 to 5998 cpm or slow-to-brisk walking ( 3.8 to $7.5 \mathrm{~km} /$ hour $)$. On average, $4 \%$ of total working time was spent in physical activity of at least vigorous intensity, that is $>5998 \mathrm{cpm}$. Sixty-one percent ( $44 \mathrm{~min}$ per day) of the time spent in activities generating $>2020 \mathrm{cpm}$ was conducted wearing combat equipment $(\geq 17.5 \mathrm{~kg})$, as illustrated in figure 4 . There was, however, a large variation across weeks in work time wearing combat equipment that spanned from $4 \%$ to $94 \%$, as exemplified in figure 5 . 
Table 5 Regression analyses of individual physical characteristics, work- and health-related risk variables: univariate and multiple final adjusted ${ }^{\dagger} \mathrm{HR}$ for low back pain limiting work ability during the marine training course

\begin{tabular}{|c|c|c|c|c|c|c|c|c|c|}
\hline \multirow[b]{2}{*}{ Variable } & \multicolumn{3}{|c|}{ Univariate } & \multicolumn{3}{|c|}{ Final crude multivariable } & \multicolumn{3}{|c|}{ Final adjusted multivariable $^{*}$} \\
\hline & HR & $95 \% \mathrm{Cl}$ & $P$ value & HR & $95 \% \mathrm{Cl}$ & $P$ value & HR & $95 \% \mathrm{Cl}$ & $P$ value \\
\hline \multicolumn{10}{|l|}{ Physical characteristics } \\
\hline Body height $\leq 1.80(\mathrm{~m})$ & 2.20 & 0.96 to 5.03 & 0.062 & 3.04 & 1.35 to 6.86 & 0.007 & 4.48 & 2.01 to 9.97 & $<0.001$ \\
\hline \multicolumn{10}{|l|}{ Rated health/health history } \\
\hline $\begin{array}{l}\text { Hip/knee pain; within } 6 \text { months prior to } \\
\text { course start }\end{array}$ & 1.15 & 0.41 to 3.23 & 0.784 & & & & & & \\
\hline $\begin{array}{l}\text { Neck/shoulder pain; within } 6 \text { months prior to } \\
\text { course start }\end{array}$ & 2.79 & 1.18 to 6.57 & 0.019 & & & & & & \\
\hline \multicolumn{10}{|l|}{ Work-related } \\
\hline Current work ability with regard to best ever & 1.74 & 0.68 to 4.40 & 0.246 & & & & & & \\
\hline \multicolumn{10}{|l|}{ Physical training; } \\
\hline$\leq 2$ sessions/week & 1.87 & 0.78 to 4.49 & 0.161 & 3.23 & 1.41 to 7.40 & 0.006 & 2.96 & 1.19 to 7.39 & 0.020 \\
\hline \multicolumn{10}{|l|}{ Muscular strength training; } \\
\hline$\leq 1$ sessions/week & 0.86 & 0.30 to 2.43 & 0.774 & & & & & & \\
\hline 2-4 sessions/week & 1.00 & & & & & & & & \\
\hline$\geq 5$ sessions/week & 1.82 & 0.79 to 4.22 & 0.161 & & & & & & \\
\hline \multicolumn{10}{|l|}{ Aerobic fitness training; } \\
\hline$\leq 1$ sessions/week & 1.41 & 0.63 to 3.15 & 0.408 & & & & & & \\
\hline
\end{tabular}

${ }^{*}$ Adjusted for confounding effect of sex and neck/shoulder pain previous to course start.

\section{DISCUSSION}

This prospective cohort study aimed to lay the foundation for LBP prevention in Swedish marines, by evaluating the occurrence of LBP and identifying early risks for such disorders in soldiers during the marine training course. The results showed a high occurrence of LBP and consequent limitations in work ability while participating in their basic training marine-course. Marines with a history of previous back pain, those with shorter body height or marines who performed poorly in the pull-up test were twice as likely to experience a new episode of LBP during this 4 month period of physically demanding marine tasks.

This study followed $95 \% \quad(n=53)$ of the participants enrolled in a typical marine training course in the SwAF. Our cohort was homogeneous with regard to demographic characteristics and occupational tasks, which is similar to previous studies of marines, ${ }^{4}$ and may be regarded as a representative military-marine sample. While the sample size constituted the majority of the eligible Swedish marine trainees, caution has been taken to avoid overfitting of statistical models. The effect of the relative small sample size on precisions of the estimate was here reflected in the somewhat wide confidence intervals. Furthermore, given the heightened risk of non-identification of a true risk factor, omission of borderline significant risks, that is not reaching significance in the present study, should not exclude them for further investigation in other similar cohorts in the military community. The loss of power could have been avoided by including data from future training courses (ie, accumulating a larger sample), other military courses or by prolonging the follow-up period (ie, including time after the course). ${ }^{38}$ For the present study's aims, however, we believe it was more important to emphasise sample homogeneity and specific work-related exposure, as we believe this to be one of the most challenging factors to control for in studies of military populations.

We believe this study to be the first to use a repeated time-to-event regression method, with discontinued risk intervals, for LBP in a military population. This method may - we believe - better reflect the recurrent nature of LBP and make more use of the collected data than the conversional methods using time-to-first event. The definitions of a new event vary between studies, ${ }^{39}$ but a pain-free period of 1 week was considered sufficient for an additional event to be defined as either a new event or symptom "flare up ${ }^{40}$ from a previous event. Given that this definition does not distinguish between a new 'uniquely' first event or symptom 'flare up' from a recurrent chain of events, potential differences in the mechanism for new and recurrent pain could not be further disentangled in this study. Regarding our baseline testing, marines that were injured $(n=9)$ or ill $(n=7)$ were not 


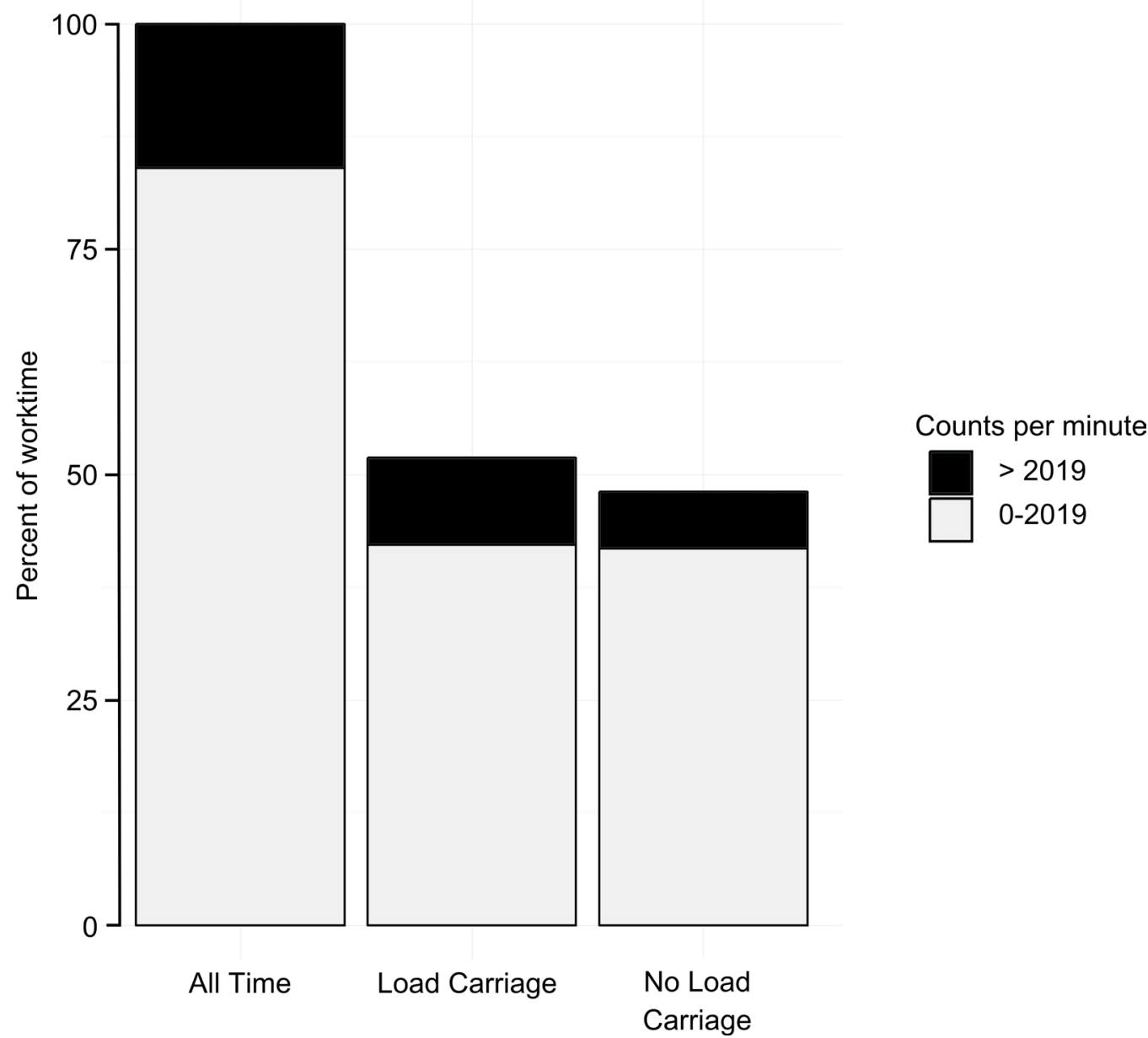

Figure 4 Proportions of work time spent in occupational physical activity generating more and less than 2020 counts per minute; in total, with and without combat load carriage $(\geq 17.5 \mathrm{~kg})$. Work time is based on an average weekly work time of 38 hours (not including long distance march training, combat obstacle course or aquatic training, constituting a weekly average of an additional 2 hours).

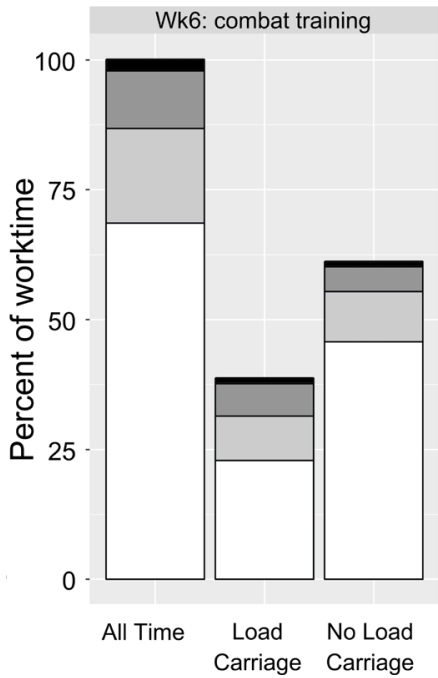

Wk7: orientation/comunication

Wk8: advanced combat training
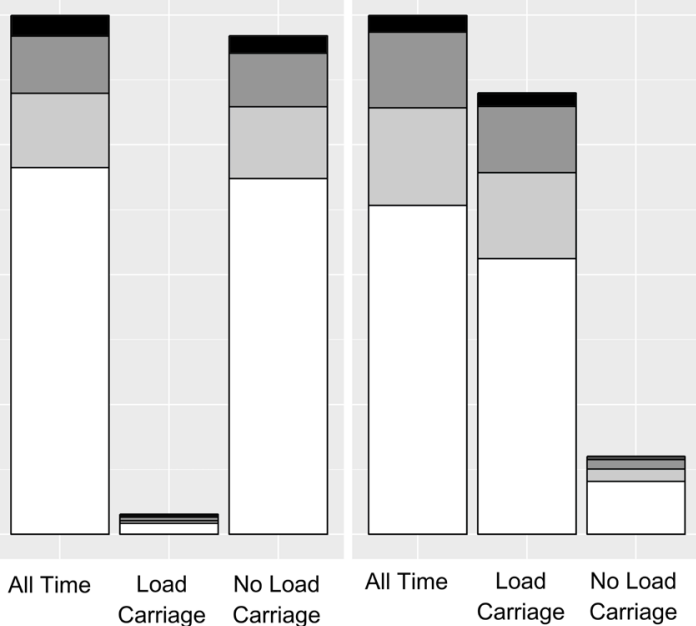

Counts per minute

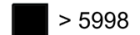

2020-5998

$100-2019$

0-99

Figure 5 Proportions of work time in occupational physical activity reported per category of physical intensity, ${ }^{38}$ for total work time and time with/without combat load carriage $(\geq 17.5 \mathrm{Kg})$ for three consecutive course weeks with different learning objectives; 'combat training (course week 6)', 'orientation and communication (course week 7)' and 'advanced combat training (course week 8)'. Wk, week. 
allowed to perform the 'max effort' tests, because of the risk of worsening their health. However, analysis based on complete cases, as well as on imputations including only males, did not change the results, indicating an appropriate inference from the present results. Due to none of the female marines conducting the two 'max' tests of pull-ups or kettle-bell lifts, these results should only be extended to males.

Our results show a relatively high incidence of LBP in this cohort of young marines, with more than two-thirds experiencing at least one LBP episode during the course. This is almost twice the reported 6 month LBP prevalence for active duty SwAF marines, ${ }^{4}$ more than twice the LBP incidence in the British combat infantryman's course, ${ }^{41}$ and higher than the total musculoskeletal injury incidence in other military training cohorts. ${ }^{42-44}$ This difference in pain occurrence may partly be explained by differences in the length of follow-up periods, ${ }^{45}$ or how LBP was defined. ${ }^{46}$ However, the recall period in this study was relatively short, and as such should limit the risk of recall bias. Given that three of five marines experiencing LBP also reported related limitations in work ability, it is likely that LBP reduced the intended goals with the course, and this may have future negative effects on the operational readiness of SwAF marine units.

Although previous musculoskeletal disorders are considered to be the strongest predictor for new musculoskeletal disorders in military populations, ${ }^{15} 434748$ it is not clear if such previous pain-episodes are anatomically region-specific in their prediction. This might not make a substantial difference in general primary prevention policy decisions, but the present findings could - we believe - help clinicians to be more specific in their selection of suitable secondary preventive measures for LBP. However, until the pathophysiological pathways between prior and future pain episodes are further disentangled, this does not inform the clinician what specific deficiencies to address. As such, the current use is limited to identifying persons at risk of $\mathrm{LBP}^{49}$; marines at risk should be considered for further clinical examination and secondary preventive action. The same goes for marines with a body height of $\leq 1.80 \mathrm{~m}$, here identified as a risk for both LBP and LBP limiting work ability. While risks associated with body height are in line with our previous results, ${ }^{4}$ it is not likely that a short body height per se constitutes the actual risk, it could potentially represent an interaction with equipment worn or specific work tasks conducted.

The present results also highlight the need for regular physical training ( $\geq 3$ sessions/week) for military personnel planning to attend the marine training course. This is in line with recommendations for general health in the civilian population, ${ }^{50}$ and should certainly be stressed for this physically active military community as well. Here, inferior upper-body strength, as tested by the pull-up test, seems to have played a role in back pain aetiology. This test, used in different forms in many military physical assessments, ${ }^{14} 51$ is considered a relevant test of the ability to navigate over obstacles, ${ }^{14}$ but also as a proxy for general upper-body strength and muscle endurance. ${ }^{52}$ The test primarily challenges the back, shoulder and arm muscles, but also to a moderate extent the external oblique and erector spinae muscles. ${ }^{53}$ As such, it could represent a valid test for marines as upper body strength is crucial for load carriage ${ }^{54}$ No female marines conducted these tests, therefore future cut-offs need to be validated for them. Neither the kettlebell lifts nor any of the movement-control tests predicted future LBP, however, 'core-strengthening exercises' were already conducted as part of the marines' daily callisthenics in this sample, potentially preventing such deficits early in the course. Still, the results tally with our previously reported results from active duty marines, where these tests, analysed as overall pass/fail, failed to predict back pain within a 6 and 12 month event window. ${ }^{15}$ While the present study aimed at identifying early risks for LBP, the sample size limited the exploration of potential effect measures modification in the final models to two-way statistical interactions. These analyses did, however, not provide any evidence of previous back pain affecting the amount of physical training and upper body strength in relation to a new back pain episode. The direction of temporality could however only be addressed for the 6 months preceding the course start. Still, physical training is recommended as primary, ${ }^{55-60}$ secondary ${ }^{55} 565860$ and tertiary ${ }^{55-60}$ preventive actions for back pain in both general populations and occupational settings. This highlights the potential role of physical training as a preventive action against future back pain episodes for marines displaying these identified risks.

While the physical demands of the course could be one reason for high LBP incidence, more than $80 \%$ of the work time measured was spent at low levels of ambulation, that is producing less than $2020 \mathrm{cpm}$. These results were similar to, or lower than, ambulatory movements reported for basic military training courses. ${ }^{61-63}$ However, in comparison with the US basic military training, where loads of no more than $4.5 \mathrm{~kg}$ were carried for $80 \%$ of the time,${ }^{61}$ the marines in the present study carried combat equipment weighing $>17.5 \mathrm{~kg}$ for more than half of the measured work time. In addition, the maximum weight of equipment worn on certain occasions, such as during loaded marches, can at times be more than twice that. Considering that both body-worn equipment and load carriage has been linked to LBP in deployed military personnel, ${ }^{12}$ this may possibly relate to the high LBP incidence in the present study. Furthermore, it highlights the need to consider load carriage when examining the association between ambulatory movement and LBP in the military context.

In summary, LBP and related limitations in work ability are common during the 4 month physically demanding marine training course, and may affect the future operational readiness of marine units. Since previous LBP episodes are the most consistent risk for further LBP, marines entering the course with a history of LBP 
should receive tailor-made secondary preventive actions. Furthermore, marines with few weekly sessions of physical training, or with insufficient upper body strength, should be considered for targeted physical training. Further investigation on the role of body height on LBP is needed, including its relation to body-worn equipment, before it can be effectively used in LBP prevention. In addition, while ambulation was low for parts of the course, combat equipment was carried for more than half of the work time, further indicating the need to consider the role of body-worn equipment in LBP aetiology for this population.

\section{Author affiliations}

${ }^{1}$ Division of Physiotherapy, Department of Neurobiology, Care Sciences and Society, Karolinska Institutet, Huddinge, Sweden

${ }^{2}$ School of Education, Health and Social Studies, Dalarna University, Falun, Sweden

${ }^{3}$ Swedish Armed Forces, Military Academy Karlberg, Stockholm, Sweden

${ }^{4}$ Swedish Armed Forces, Headquarters, Medical Services, Stockholm, Sweden

${ }^{5}$ Department of Orthopedics, Faculty of Medicine, Lund University, Lund, Sweden

${ }^{6}$ Centre for Musculoskeletal Research, Department of Occupational Health Science and Psychology, University of Gävle, Gävle, Sweden

${ }^{7}$ Center for Clinical Research, Uppsala University, Falun, Sweden

Acknowledgements Funding from the Swedish Armed Forces PhD program and financial support from the Swedish Society for Military Medical Officers, Ann-Marie och Ragnar Hemborgs Minnesfond and Stiftelsen fond till minne av ömsesidiga Olycksfallsförsäkringsbolaget Landoch Sjö is gratefully acknowledged. In addition, we would like to thank the 1st Marine Regiment of the Swedish Armed Forces for overall support. The authors would also like to thank Jacob Sejersen and Kjell Norman for valuable support during design of the study and during data collection.

Contributors AM was the main writer of the paper and participated in the conception and design of the study, and acquired, analysed and interpreted the data. HL and HN participated in the conception and design of the study, planning of the analysis, interpretation of the data as well as the writing and revising of the paper. MD was involved in the design and planning of the study, as well as interpreting the data and revising the paper. As senior project researcher, BOÄ participated in the conception and design of the study, planning the analysis and interpretation of the data and writing and revising the paper. All the authors have read and approved the final manuscript.

Funding Funding was received from the Swedish Armed Forces PhD program, the Swedish Society for Military Medical Officers, Ann-Marie och Ragnar Hemborgs Minnesfond and Stiftelsen fond till minne av ömsesidiga Olycksfallsförsäkringsbolaget Landoch Sjö. The funding organisations had no authority over or input into any part of the study.

Competing interests Dr AM reports grants from The Swedish Society for Military Medical Officers, grants from Ann-Mari och Ragnar Hemborgs Minnesfond, grants from Stiftelsen fond till minne av ömsesidiga Olycksfallsförsäkringsbolaget Land och Sjö, during the conduct of the study; Dr HL has nothing to disclose. Dr HN has nothing to disclose. Dr MD has nothing to disclose. Dr BOÄ has nothing to disclose.

Patient consent for publication Not required.

Provenance and peer review Not commissioned; externally peer reviewed.

Data sharing statement № additional data are available.

Open access This is an open access article distributed in accordance with the Creative Commons Attribution Non Commercial (CC BY-NC 4.0) license, which permits others to distribute, remix, adapt, build upon this work non-commercially, and license their derivative works on different terms, provided the original work is properly cited, appropriate credit is given, any changes made indicated, and the use is non-commercial. See: http://creativecommons.org/licenses/by-nc/4.0/.

\section{REFERENCES}

1. Global Burden of Disease Study 2013 Collaborators. Global, regional, and national incidence, prevalence, and years lived with disability for 301 acute and chronic diseases and injuries in 188 countries, 1990-
2013: a systematic analysis for the Global Burden of Disease Study 2013. Lancet 2015;386:743-800.

2. Hoy D, Bain C, Williams G, et al. A systematic review of the global prevalence of low back pain. Arthritis Rheum 2012;64:2028-37.

3. Katz JN. Lumbar disc disorders and low-back pain: socioeconomic factors and consequences. J Bone Joint Surg Am 2006;88(supp 2):21-4.

4. Monnier A, Larsson H, Djupsjöbacka M, et al. Musculoskeletal pain and limitations in work ability in Swedish marines: a crosssectional survey of prevalence and associated factors. BMJ Open 2015;5:e007943.

5. Hayton J. Reducing medical downgrading in a high readiness Royal Marine Unit. J R Army Med Corps 2004;150:164-7.

6. Pengel LH, Herbert RD, Maher CG, et al. Acute low back pain: systematic review of its prognosis. BMJ 2003;327:323.

7. Piantanida NA, Knapik JJ, Brannen S, et al. Injuries during Marine Corps officer basic training. Mil Med 2000;165:515-20.

8. Trone DW, Cipriani DJ, Raman R, et al. Self-reported smoking and musculoskeletal overuse injury among male and female U.S. Marine Corps recruits. Mil Med 2014;179:735-43.

9. Papageorgiou AC, Croft PR, Thomas E, et al. Influence of previous pain experience on the episode incidence of low back pain: results from the South Manchester Back Pain Study. Pain 1996;66:181-5.

10. Adams MA, Mannion AF, Dolan P. Personal risk factors for first-time low back pain. Spine 1999;24:2497.

11. Feyer AM, Herbison P, Williamson AM, et al. The role of physical and psychological factors in occupational low back pain: a prospective cohort study. Occup Environ Med 2000;57:116-20.

12. Roy TC, Lopez HP, Piva SR. Loads worn by soldiers predict episodes of low back pain during deployment to Afghanistan. Spine 2013;38:1310-7.

13. Taanila H. Musculoskeletal disorders in male Finnish conscripts: Importance of physical fitness as a risk factor, and effectiveness of neuromuscular exercise and counseling in the prevention of acute injuries, and low back pain and disability. (Doctoral dissertation, University of Tampere, School of Medicine, UKK Institute, Centre for Military Medicine Finland, 2013). http://urn.fi/URN:ISBN:978-951-449069-9.

14. Larsson $\mathrm{H}$, Tegern $\mathrm{M}$, Monnier $\mathrm{A}$, et al. Content validity index and intra- and inter-rater reliability of a new muscle strength/endurance test battery for Swedish Soldiers. PLoS One 2015;10:e0132185.

15. Monnier A, Djupsjöbacka M, Larsson $\mathrm{H}$, et al. Risk factors for back pain in marines; a prospective cohort study. BMC Musculoskelet Disord 2016;17:319.

16. Ilmarinen J. The Work Ability Index (WAI). Occup Med 2007;57:160.

17. Goldberg DP, Gater R, Sartorius N, et al. The validity of two versions of the GHQ in the WHO study of mental illness in general health care. Psychol Med 1997;27:191-7.

18. Kuorinka I, Jonsson B, Kilbom A, et al. Standardised Nordic questionnaires for the analysis of musculoskeletal symptoms. Appl Ergon 1987; 18:233-7.

19. Monnier A, Heuer J, Norman K, et al. Inter- and intra-observer reliability of clinical movement-control tests for marines. BMC Musculoskelet Disord 2012;13:263.

20. Larsson $\mathrm{H}$, Larsson $\mathrm{M}$, Osterberg $\mathrm{H}$, et al. Screening tests detect knee pain and predict discharge from military service. Mil Med 2008;173:259-65.

21. Larsson $\mathrm{H}$, Harms-Ringdahl K. A lower-limb functional capacity test for enlistment into Swedish Armed Forces ranger units. Mil Med 2006;171:1065-70.

22. Comerford MJ. The Performance Matrix performance Profiling, risk assessment \& training strategies for injury prevention \& performance enhancement. UK: KC International / Movement Performance Solutions, 2008.

23. Hoy D, March L, Brooks P, et al. Measuring the global burden of low back pain. Best Pract Res Clin Rheumatol 2010;24:155-65

24. Hosmer DW, Lemeshow S, May S. Applied survival analysis: regression modelling of time to event data. 2nd edn. Hoboken: John Wiley \& Sons, 2008.

25. Vittinghoff E, Glidden D, Shiboski S, et al. Regression methods in biostatistics: linear, logistic, survival, and repeated measures models. New York: Springer, 2005.

26. Rubin DB. Multiple imputation after 18+ years. J Am Stat Assoc 1996:91:473-89.

27. Brown LD, Cai TT, DasGupta A. Interval estimation for a binomial proportion. Statist Sci 2001.

28. Miller RG. The jackknife-a review. Biometrika 1974;61:1-15.

29. Choi L, Liu Z, Matthews CE, et al. Validation of accelerometer wear and nonwear time classification algorithm. Med Sci Sports Exerc 2011;43:357-64. 
30. Troiano RP, Berrigan D, Dodd KW, et al. Physical activity in the United States measured by accelerometer. Med Sci Sports Exerc 2008;40:181-8.

31. Nichols JF, Morgan CG, Chabot LE, et al. Assessment of physical activity with the Computer Science and Applications, Inc., accelerometer: laboratory versus field validation. Res $Q$ Exerc Sport 2000;71:36-43.

32. Matthew CE. Calibration of accelerometer output for adults. Med Sci Sports Exerc 2005;37(11 Suppl):S512-22.

33. Andersen PK, Gill RD. Cox's Regression model for counting processes: a large sample study. The Annals of Statistics 1982;10:1100-20.

34. Guo Z, Gill TM, Allore HG. Modeling repeated time-to-event health conditions with discontinuous risk intervals. An example of a longitudinal study of functional disability among older persons. Methods Inf Med 2008;47:107.

35. Lin DY, Wei LJ. The robust inference for the cox proportional hazards model. J Am Stat Assoc 1989;84:1074-8.

36. Vittinghoff $E$, McCulloch CE. Relaxing the rule of ten events per variable in logistic and Cox regression. Am J Epidemiol 2007;165:710-8.

37. Cleves M, Gould W, Gutierrez R, et al. An introduction to survival analysis using Stata. 3ed edn. College Station: Stata press, 2010.

38. Ingel K, Jahn-Eimermacher A. Sample-size calculation and reestimation for a semiparametric analysis of recurrent event data taking robust standard errors into account. Biom J 2014;56:631-48.

39. Stanton TR, Latimer J, Maher CG, et al. How do we define the condition 'recurrent low back pain'? A systematic review. Eur Spine $J$ 2010;19:533-9.

40. Young AE, Wasiak R, Phillips L, et al. Workers' perspectives on low back pain recurrence: "it comes and goes and comes and goes, but it's always there". Pain 2011;152:204-11.

41. Sharma J, Greeves JP, Byers M, et al. Musculoskeletal injuries in British Army recruits: a prospective study of diagnosis-specific incidence and rehabilitation times. BMC Musculoskelet Disord 2015;16:1): 1

42. Taanila $\mathrm{H}$, Suni $\mathrm{JH}$, Kannus $\mathrm{P}$, et al. Risk factors of acute and overuse musculoskeletal injuries among young conscripts: a populationbased cohort study. BMC Musculoskelet Disord 2015;16:1):1

43. Knapik JJ, Graham B, Cobbs J, et al. A prospective investigation of injury incidence and injury risk factors among Army recruits in military police training. BMC Musculoskelet Disord 2013;14:32.

44. Hollingsworth DJ. The prevalence and impact of musculoskeletal injuries during a pre-deployment workup cycle: survey of a Marine Corps special operations company. J Spec Oper Med 2009;9:11.

45. Carragee EJ, Cohen SP. Lifetime asymptomatic for back pain: the validity of self-report measures in soldiers. Spine 2009;34:978-83.

46. Thiese MS, Hegmann KT, Wood EM, et al. Prevalence of low back pain by anatomic location and intensity in an occupational population. BMC Musculoskelet Disord 2014;15:15(1):1.

47. Mattila VM, Sahi T, Jormanainen V, et al. Low back pain and its risk indicators: a survey of 7,040 Finnish male conscripts. Eur Spine $J$ 2008;17:64-9.

48. Knapik JJ, Graham B, Cobbs J, et al. A prospective investigation of injury incidence and risk factors among army recruits in combat engineer training. J Occup Med Toxicol 2013;8:5.

49. Leboeuf-Yde C. Back pain--individual and genetic factors. $J$ Electromyogr Kinesiol 2004;14:129-33.
50. Garber CE, Blissmer B, Deschenes MR, et al. American College of Sports Medicine position stand. Quantity and quality of exercise for developing and maintaining cardiorespiratory, musculoskeletal, and neuromotor fitness in apparently healthy adults: guidance for prescribing exercise. Med Sci Sports Exerc 2011;43:1334-59.

51. Headquarters Marine Corps. Marine corps physical fitness test and body composition program manual. Washington, DC, 2002.

52. Vickers Jr RR. Construct validity of physical fitness tests. San Diego: Naval Health Research Center, 2011. Report. No. 11-52.

53. Youdas JW, Amundson CL, Cicero KS, et al. Surface electromyographic activation patterns and elbow joint motion during a pull-up, chin-up, or perfect-pullup ${ }^{\mathrm{TM}}$ rotational exercise. J Strength Cond Res 2010;24:3404-14.

54. Knapik JJ, Harman EA, Steelman RA, et al. A systematic review of the effects of physical training on load carriage performance. $J$ Strength Cond Res 2012;26:585-97.

55. Burton AK, Balagué F, Cardon G, et al. Chapter 2. European guidelines for prevention in low back pain: November 2004. Eur Spine J 2006;15:s136-68.

56. Burton AK, Balagué F, Cardon G, et al. How to prevent low back pain. Best Pract Res Clin Rheumatol 2005;19:541-55.

57. Bigos SJ, Holland J, Holland C, et al. High-quality controlled trials on preventing episodes of back problems: systematic literature review in working-age adults. Spine J 2009;9:147-68.

58. Schaafsma FG, Anema JR, van der Beek AJ. Back pain: prevention and management in the workplace. Best Pract Res Clin Rheumatol 2015;29:483-94.

59. Steffens D, Maher CG, Pereira LS, et al. Prevention of low back pain: a systematic review and meta-analysis. JAMA Intern Med 2016;176:199-208.

60. Shiri R, Coggon D, Falah-Hassani K. Exercise for the prevention of low back pain: systematic review and meta-analysis of controlled trials. Am J Epidemiol 2018;187:1093-101.

61. Simpson K, Redmond JE, Cohen BS, et al. Quantification of physical activity performed during US Army Basic Combat Training. US Army Med Dep J 2013;4:55-65.

62. Roos L, Boesch M, Sefidan S, et al. Adapted marching distances and physical training decrease recruits' injuries and attrition. Mil Med 2015;180:329-36.

63. Wyss T, Roos L, Hofstetter MC, et al. Impact of training patterns on injury incidences in 12 Swiss Army basic military training schools. Mil Med 2014;179:49-55.

64. Goldberg DP, Williams P. A User's Guide to the General Health Questionnaire. 3rd edn. London, UK: NFER, 1988.

65. Makowska Z, Merecz D, Mościcka A, et al. The validity of general health questionnaires, GHQ-12 and GHQ-28, in mental health studies of working people. Int $J$ Occup Med Environ Health 2002;15:353-62.

66. Fredriksson K, Alfredsson L, Ahlberg G, et al. Work environment and neck and shoulder pain: the influence of exposure time. Results from a population based case-control study. Occup Environ Med 2002;59:182-8.

67. Vingård $\mathrm{E}$, Alfredsson L, Hagberg $\mathrm{M}$, et al. To what extent do current and past physical and psychosocial occupational factors explain care-seeking for low back pain in a working population? Results from the Musculoskeletal Intervention Center-Norrtälje Study. Spine 2000;25:493-500. 